\title{
Dakwah Muhammadiyah Melalui Lembaga Pendidikan
}

\section{Herman Tahang, Ismail Suardi Wekke, Fatimah Fatimah}

\author{
Sekolah Tinggi Agama Islam Negeri (STAIN) Sorong
}

\section{A. Latar Belakang Masalah}

Wacana tentang Muhammadiyah, seakan perlu menghadirkan sosok K.H.Ahmad Dahlan sebagai tokoh sentral pembaharu pendidikan, sosial dan keagamaan. Muhammadiyah sebagai salah satu organisasi keagamaan terbesar di Indonesia memegang peranan penting dalam sejarah perjalanan bangsa Indonesia sejak pra kemerdekaan hingga mengantarkan bangsa ini memproklamasikan kemerdekaannya sampai saat sekarang. Peran tersebut tidak terlepas dari maksud dan tujuan pendirian Muhammadiyah dalam rangka menegakkan dan menjunjung tinggi agama Islam semata-mata demi terwujudnya 'Izzul Islam wal Muslimin, kejayaan Islam sebagai realita dan kemuliaan hidup umat Islam. ${ }^{1}$

Muhammadiyah tersebar diseluruh Indonesia tidak terlepas dari itu Organisasi Muhammadiyah ini hadir Kota Sorong pada tahun 1990-an. Kedatangan Muhammadiyah di Kota Sorong memberikan angin segar bagi kalangan para imigran, awalnya ormas ini datang hanya dengan tujuan dakwah dan memperluas jaringan pengkaderan, namun melihat kondisi masyarakat di Kota Sorong masih sangat terbelakang baik dalam masalah kehidupan maupun

1 Syafiq A. Mughni, Makalah Seminar Pra-Muktamar Muhammadiyah Ke-46, di Universitas Muhammadiyah Sumatera Utara, 2009. 
pendidikan sehingga organisasi Muhammadiyah ini tergerak untuk membantu mengembangkan kualitas masyarakat Papua khususnya masyarakat imigran yang berdomisili di Kota Sorong.

Pergerakan Muhammadiyah ini dimulai dari pergerakan personal dilakukan dengan memberikan arahan dan pengajaran secara pribadi serta pergerakan nyata yang dibuktikan dengan membangun lembaga-lembaga pendidikan Islam yang sangat beragam dan berjenjang dimulai dari Taman Kanak-kanak hingga Perguruan Tinggi. Lembaga pendidikan Muhammadiyah diperkirakan akan terus bertambah, karena sesuai prioritas pengembangan kualitas dan misi pendidikan Muhammadiyah di seluruh jenjang melalui perencanaan strategi yang dapat mencapai tujuan pendidikan sebagaimana cita-cita pendiri Muhammadiyah dan sekaligus menjadi ciri khas pendidikan Islam dan Institusi pendidikan dan kebudayaan Islam.

Muhammadiyah adalah organisasi yang berasaskan Islam, maksud dan tujuan Muhammadiyah yang paling esensi adalah untuk menyebarkan agama Islam baik melalui jalur pendidikan maupun kegiatan sosial lainnya. Selain itu Muhammadiyah bertujuan untuk meluruskan keyakinan yang menyimpan dalam masyarakat serta menghapus perbuatan yang dianggap oleh Muhammadiyah sebagai bid'ah. Ada dua faktor yang mendorong lahirnya Muhammadiyah yaitu faktor intern dan faktor ekstern. ${ }^{2}$ Faktor intern ialah keadaan yang terdapat dikalangan umat Islam sendiri, yakni tersebut antara lain; praktek kehidupan

${ }^{2}$ Siti Amanati, Pendidikan Kemuhammadiyahan, (Cet. I., Yogyakarta: Dikdasmen PW Muhammadiyah, 2010), h. 21-25. 
beragama yang sudah dianggap menyimpan dari ajaran agama yang sebenarnya menurut Alquran dan Sunnah Rasul.

Keadaan sosial ekonomi sebagian umat Islam sangat rendah, sebagai akibat dari kolonialisme Belanda. Tidak terdapat suatu organisasi Islam yang kuat yang dapat memperjuangkan nasib umat Islam. Sistem pendidikan pondok yang ada tidak mendukung kemajuan umat yang diharapkan sesuai dengan tuntutan zaman. Sedangkan faktor-faktor ekstern antara lain; sifat kolonialisme Belanda yang tidak memperhatikan kepentingan rakyat Indonesia yang sepenuhnya mendapat bantuan dari pemerintah Belanda. Muhammadiyah adalah organisasi yang lahir sebagai organisasi Islam pembaharu dan dapat mengantisipasi berbagai persoalan yang dihadapi umat Islam Indonesia sekitar abad ke-19 dan awal abad ke-20.

Muhammadiyah merupakan konsekuensi logis munculnya pertanyaan sederhana seorang muslim kepada diri dan masyarakatnya tentang bagaimana memahami dan mengamalkan kebenaran Islam agar hal-hal yang telah dialami sebagai pesan global Islam "Rahmatan lil Alamin" atau kesejahteraan bagi seluruh alam dapat diwujudkan dalam kehidupan obyektif umat manusia. Dari hal tersebut, maka kelahiran Muhammadiyah merupakan bagian dari daya kreatif umat Islam Indonesia. Olehnya itu, maka sejarah perkembangan Muhammadiyah adalah bagian dinamika dan dinamisme daya kreatif intelek manusia muslim dari berbagai persoalan hidupnya dengan norma ajaran Islam. ${ }^{3}$

\footnotetext{
${ }^{3}$ Abdul Munir Mulkhan. Pemikiran Kyai Haji Ahmad Dahlan, Muhammadiyah dalam Perspektif Perubahan Sosial, (Cet. I., Jakarta: Bumi Aksara, 1990), h. 1
} 
Perkembangan Muhammadiyah sebagai organisasi gerakan Islam, gerakan dakwah dan gerakan tajdid menyesuaikan perpaduan historis antara dimensi normatif (wahyu) dengan dunia obyektif berupa daya kreatif manusia. Perpaduan tersebut telah mendorong dinamika sejarah yang selalu berkembang dan berubah. Pemahaman Kyai H. Ahmad Dahlan terhadap wahyu, khususnya ayat 40 dalam surat Ali Imran dan realitas pemahaman ajaran Islam masyarakat telah mendorong Kyai Ahmad Dahlan mendirikan Muhammadiyah. Ayat 40 dalam surah tersebut ini mengandung makna agar ada organisasi yang mengkhususkan diri dalam gerakan dakwah amar ma'ruf nahi mungkar untuk membebaskan manusia dari kebodohan, kesengsaraan dan kemelaratan.

Muhammadiyah sebagai organisasi yang bergerak di bidang pendidikan, dakwah dan kemasyarakatan dengan pola dasar perjuangannya dakwah, amal ma'ruf nahi mungkar sebagai salah satu pemahaman firman Allah dalam Q.S. Ali Imran ayat 104. Muhammadiyah se-Indonesia mengembangkan amal dan usaha tidak terkecuali di Kota Sorong. Setiap anggota Muhammadiyah punya kewajiban perihatiin dengan lingkungannya, terutama di bidang pendidikan. Hal inilah yang dapat dilihat di Kota Sorong, Muhammadiyah membangun lembaga pendidikan dari hasil solidaritas para anggota-nya.

Berdasarkan hal tersebut, maka dalam kajian ini, akan meneliti bagaimana dakwah organisasi ini dalam menjawab tantangan zaman, menata organisasinya dengan berbagai dinamika internal dan eksternal yang semakin tinggi, terkadang mempertahankan jauh lebih sulit daripada membangun diawal. Dengan semangat beramal ma'ruf nahi mungkar, apakah Muhammadiyah masih eksis dengan 
selogan ini dalam dakwah, pendidikan dan penyantung. Skripsi ini akan membahas "Dakwah Muhammadiyah Melalui Lembaga Pendidikan" dalam konteks yang lebih mikro yakni di Kota Sorong.

\section{B. Rumusan Masalah}

Berdasarkan latar belakang tersebut, maka rumusan yang diangkat adalah "Bagaimana Dakwah Muhammadiyah Melalui Lembaga Pendidikan di Kota Sorong". Adapun untuk menjawab rumusan masalah tersebut, maka dapat dirumuskan beberapa masalah:

1. Bagaimana wujud dakwah Muhammadiyah di bidang pendidikan di Kota Sorong?

2. Bagaimana strategi dakwah Muhammadiyah melalui lembaga pendidikan di Kota Sorong?

\section{Tujuan}

Berdasarkan rumusan masalah di atas, maka tujuan melakukan penelitian ini adalah:

1. Menguraikan wujud dakwah Muhammadiyah di bidang pendidikan di Kota Sorong.

2. Mengidentifikasi strategi dakwah Muhammadiyah melalui lembaga pendidikan di Kota Sorong.

\section{Manfaat}


Secara teoritis, hasil penelitian ini diharapkan akan mendukung teori yang telah ada, dapat bermanfaat dalam menambah ilmu pengetahuan bagi pengembangan intelektual dan memperkaya kajian di bidang dakwah, khususnya mengenai dakwah Muhammadiyah dalam mengaplikasikan amal dan usaha Muhammadiyah.

Secara praktisi, hasil penelitian ini dapat memberikan sumbangan ilmiah yang berarti dalam kajian dakwah Muhammadiyah dan dapat pula digunakan sebagai tambahan informasi bagi pihak instansi pemerintah dan swasta, akademisi, serta masyarakat pada umunya dan khususnya Pimpinan Daerah Muhammadiyah Kota Sorong, yang tertarik dengan masalah ini, untuk melakukan penelitian atau pengembangan yang lebih baik di masa mendatang.

\section{E. Pengertian Judul}

Dakwah secara bahasa merupakan sebuah kata bahasa arab dalam bentuk masdar. Kata dakwah berasal dari kata $d a^{\prime} a$, yad'u, da'watan yang berarti seruan, panggilan, undangan atau doa. Menurut Abdul Aziz, secara etimologi kata dakwah berarti memanggil, menyeruh, menegaskan atau membela sesuatu dan memohon meminta atau doa. Artinya proses penyampaian pesan-pesan tertentu berupa ajakan, seruan, undangan untuk mengikuti pesan tersebut atau dengan tujuan untuk mendorong seseorang supaya melakukan cita-cita tertentu. ${ }^{4}$ Oleh

\footnotetext{
${ }^{4}$ Wahyu Ilahi dan Hefni Harjani, Sejarah Dakwah, (Jakarta: Kencana, 2010) h. 1-3
} 
karena itu, dalam kegiatannya ada proses mengajak, maka yang mengajak disebut da'i dan orang yang diajak disebut mad'u. ${ }^{5}$

Tujuan utama dakwah ialah mewujudkan kebahagiaan dan kesejahteraan hidup di dunia dan akahirat yang diridhoi Allah. Nabi Muhammad Saw. mencontohkan dakwah kepada umatnya dengan berbagai cara melalui lisan, tulisan dan perbuatan. Di mulai dari istrinya, keluarganya, dan teman-teman karibnya hingga raja-raja yang berkuasa pada saat itu. Beberapa pengertian dakwah menurut para ahli, sebagai berikut: ${ }^{6}$

a. Menurut M. Nasir, dakwah adalah usaha-usaha menyeruh dan menyampaikan kepada perorangan manusia dan seluruh umat tentang konsepsi Islam tentang pandangan dan tujuan hidup di dunia.

b. Menurut epositi, secara semantik dakwah berarti memanggil, mempersiapkan, memohon, propaganda dan menyebarkan.

c. Menurut Ali Mafudz, dakwah adalah mendorong (memotivasi) manusia untuk melakukan kebaikan dan mengikuti petunjuk serta memerintahkan mereka berbuat ma'ruf dan mencegah dari perbuatan mungkar agar memperoleh kebaikan dunia akhirat.

Berdasarkan pengertian diatas, maka dapat disimpulkan bahwa, dakwah adalah sebuah proses untuk menyeruh, mengajak, bisa juga diartikan dengan mengingatkan dan menyebarluaskan ajaran Islam kepada seluruh umat manusia demi keselamatan di dunia dan akhirat. Dalam konteks penelitian ini, dakwah

\footnotetext{
${ }^{5}$ Wahidin Saputra, Pengantar Ilmu Dakwah, (Cet.II., Jakarta: Raja Grafindo Persada, 2012), h. 1

${ }^{6}$ Wahyu Ilahi, Komunikasi Dakwah, (Cet.I., Bandung: Remaja Rosdakarya, 2008), h. 16
} 
yang dimaksud adalah mengajak umat manusia untuk menuntut ilmu secara formal.

Muhammadiyah adalah berasal dari bahasa Arab yang berarti "Muhammad" adalah nama rasul terakhir Muhammad Saw., kata "iyah" berarti pengikut, jadi Muhammadiyah adalah pengikut Nabi Muhammad Saw. atau umat Islam yang mengikuti, mencintai dan menghidupkan sunnah, serta melangsungkan usaha dakwah Islam a'mar ma'ruf nahi munkar. Muhammadiyah juga diartikan sebagai sebuah organisasi gerakan dakwah amar makruf nahi mungkar dengan tujuan untuk meningkatkan kualitas dakwah dan pendidikan. Berdasarkan pengertian tersebut, maka dapatlah di pahami bahwa Muhammadiyah adalah organisasi yang berusaha untuk memurnikan ajaran agama Islam dan meningkatkan mutu dakwah Islamiyah.

Lembaga pendidikan adalah badan usaha yang bergerak dan bertanggung jawab atas terselenggaranya pendidikan terhadap anak didik. Menurut Enung K. Rukiyati dan Fenti Himawati lembaga pendidikan adalah wadah atau tempat berlangsungnya proses pendidikan yang bersama an dengan proses pembudayaan. Lembaga Pendidikan juga merupakan tempat berlangsungnya proses pendidikan yang meliputi pendidikan keluarga, sekolah danmasyarakat. Lembaga pendidikan adalah tempat berlangsungya pendidikan, khususnya pada tiga lingkungan utama pendidikan itu keluarga, sekolah dan masyarakat. Jadi lembaga Pendidikan adalah tempat berlangsungnya proses pendidikan

Secara sederhana dan umum, pendidikan bermakna sebagai usaha untuk menumbuhkan dan mengembangkan potensi-potensi bawaan, baik jasmani 
maupun rohani, sesuai dengan nilai-nilai yang ada dalam masyarakat. ${ }^{7}$ Pendidikan juga diartikan sebagai usaha untuk membina kepribadian sesuai dengan nilai-nilai di dalam masyarakat dan kebudayaan. Selanjutnya pendidikan diartikan sebagai usaha yang dijalankan oleh orang atau kelompok agar menjadi dewasa atau mencapai tingkat hidup yang lebih tinggi dalam arti mental. ${ }^{8}$ Jadi, pendidikan yang dimaksud adalah usaha sadar dan terencana untuk mengembangkan potensi peserta didik sesuai dengan nilai-nilai yang terdapat dalam masyarakat.

\section{F. Kerangka Teori}

Dakwah menurut Islam adalah mengajak manusia secara kebijakan kepada jalan yang benar sesuai dengan perintah Allah untuk kemaslahatan dan kebahagiaan mereka di dunia dan akhirat. Dakwah adalah kewajiban bagi kaum muslimin untuk melaksanakannya, karena dakwah merupakan nafas dan sumber gerakan Islam. Dengan dakwah, ajaran Islam dapat tersebut, secara merata dalam masyarakat, yang dimulai pada masa Rasulullah Saw. dilanjutkan kepada para sahabat, selanjutnya kepada generasi sesudahnya sampai kita sekarang.

Oleh karena itu, dalam kegiatan ada proses mengajak, maka orang mengajak disebut dai dan orang yang diajak disebut da'i. Ada tiga macam dakwah, ${ }^{9}$ yaitu dakwah bil lisan yaitu dakwah yang dilaksanakan melalui lisan,

\footnotetext{
${ }^{7}$ Fuad Ihsan, Dasar-dasar Kependidikan (Jakarta: Rineka Cipta, 2004), h. 1-2.

${ }^{8}$ Hasbullah, Dasar-dasar Ilmu Pendidikan (Cet.I; Jakarta: Raja Grafindo Persada, 1999), h. 1 .

${ }^{9}$ Ilyas Ismail, Filsafat Dakwah (Rekayasa Membangun Agama dan Peradaban Islam), (Cet.1, Jakarta: Kencana, 2011), h. 28.
} 
yang dilakukan antara lain dengan ceramah-ceramah, khutbah, diskusi, nasihat dan lain-lain. Dakwah bil hal yaitu dakwah dengan perbuatan nyata dimana aktifitas dakwah dilakukan dengan melalui keteladanan dan tindakan amal nyata. Dakwah bil qalam yaitu dakwah melalui tulisan yang dilakukan dengan keahlian menulis di surat kabar, majalah, buku maupun internet.

Muhammadiyah adalah gerakan Islam yang melaksanakan dakwah ma'ruf nahi mungkar dan tujuan menegakkan dan menjunjung tinggi agama Islam sehingga terwujud masyarakat Islam yang sebenar-benarnya. Pada tahun 1963 Muhammadiyah hadir di Kota Sorong dengan pendirian amal usaha, terutama amal usaha di bidang pendidikan. ${ }^{10}$ Muhammadiyah adalah sebuah gerakan Islam, alat untuk mencapai maksud dan tujuan dakwah Islam, organisasi yang berdiri berdasarkan Alquran dan Sunnah Rasul. ${ }^{11}$ Organisasi Muhammadiyah adalah Persyarikatan yang merupakan gerakan Islam. Maksudya adalah dakwah amar ma'ruf nahi mungkar yang ditujukan kepada dua bidang perseorangan dan masyarakat. $^{12}$

Pendidikan Islam adalah pendidikan yang berdasarkan ajaran Islam atau tuntutan agama Islam dalam usaha membina dan membentuk pridabi muslimyang bertakwa kepada Allah Swt. ${ }^{13}$ Pendidikan Islam merupakan salah satu disiplin ilmu ke Islaman yang membahas objek-objek di seputar kependidikan. Pemahaman hakikat pendidikan Islam sebenarnya tercermin didalam sejarah dan

${ }^{10}$ Barulazi, skripsi Aktivitas Muhammadiya Dalam Dakwah Bil Hal Di Kota Sorong; Perspekstif Gerakan Pendidikan Dan Sosial”.'(Cet.II, Sorong : STAIN Sorong Press 2013), h. 193

11 M. Margono Poespa Suwarno, Gerakan Muhammadiyah, (Cet.IV.,Yogyakaarta: Persatuan Offiset, 1995), h. 17

${ }^{12}$ Sudarno Shabron, Studi Kemuhammadiyahan, (Cet.VII, Surakarta, LPID, 2008), h.90.

${ }^{13}$ Beni Ahmad Saebani, Ilmu Pendidikan Islam, (Bandung: Pustaka Setia, 2009), h. 12. 
falsafah Islam sendiri, sebab setiap proses pendidikan tidak terlepas dari objekobjek ke Islam. ${ }^{14}$ Pendidikan Islam adalah proses mengubah tingka laku individu pada kehidupan pribadi, masyarakat, dan sekitarnya, dengan cara pengajaran sebagai suatu aktivitas asasi dan sebagai prosesi di antara profesi-prosesi asasi dalam masyarakat. ${ }^{15}$.

Pendidikan bukan sekedar mengisi bejana dengan air, tetapi pendidikan adalah meyalakan api dalam kegelapan. Kehidupan tanpa pendidikan seperti halnya agama tanpa buku. Di Indonesia kesadaran akan pentingnya pendidikan dan keilmuan masyarakat diawali, salah satunya adalah oleh Muhammadiyah yang kini gerak dalam lintasannya yang mencapai sampai satu abad. Dalam konteks sejarah, dengan kepeloporannya di bidang pendidikan, Muhammadiyah telah memberikan sumbangan berharga bagi bangsa ini yakni melahirkan generasi bangsa ini yang cerdas iman, kepribadian dan alam pikirannya serta mampu ranah.Masyarakat luas mengenal dan mengedentifikasikan Muhammadiyah sebagai gerakan pendidikan.

Organisasi Muhammadiyah bergerakan di bidang pendidikan yang menjadi salah satu usaha dalam bentuk amal usaha. Dalam Anggaran Rumah Tangga Muhammadiyah tahun 2005, yang berkaitan dengan usaha di bidang pendidikan ialah $^{16}$ (1) meningkatkan harkat, martabat, dan kualitas sumber daya manusia agar berkemampuan tinggi serta berakhlak mulia, (2) memajukan dan

\footnotetext{
2008), h.67

${ }^{14}$ Hasniyati Gani Ali, Ilmu Pendidikan Islam, (Cet. I., Jakarta, Quantum Teaching,

${ }^{15}$ Bukhari Umar, Ilmu Pendidikan Islam, (Cet.I., Jakarta: Amzah, 2010), h. 208.

${ }^{16}$ Pimpinan Pusat Muhammadiyah , Anggaran Dasar dan Anggaran Rumah Tangga Muhammadiyah, (Yogyakarta; Pecetakan Persatuan, 2005), h. 98
} 
memperbaharui pendidikan dan kebudayaan, serta meningkatkan penelitian. Sistem yang diinginkan Muhammadiyah di atas berlaku pula pola pendidikan yang di bangun di Kota Sorong. Karena dilatarbelakangi ingin melihat umat Islam berkipra di dunia pendidikan dan beramal usaha, maka dipandang mendesak didirikan oleh Muhammadiyah.

Dari uraian dikemukakan di atas maka dapat di pahami bahwa dakwah Muhammadiyah adalah mengajak kepada masyarakat pentingya pendidikan, sehingga Muhammadiyah mendirikan lembaga pendidikan Islam di Kota Sorong.

\section{G. Penelitian Terdahulu}

Nurjannah, "Eksistensi Muhammadiyah Dalam Menyebarkan Agama Islam Di Desa Masalle Buntu Sarong Kecamatan Alla Kabupaten Enrekang”. Pokok pembahasannya tentang mencegah kemusyirkan (animisme) dan memberikan pemahaman bahwa pendidikan bukan hanya orang-orang yang berdarah biru atau para kaum bangsawan.

Barulazi, "Aktivitas Muhammadiyah Dalam Dakwah Bil Hal Di Kota Sorong; Perspekstif Gerakan Pendidikan Dan Sosial”. Pokok masalahnya tentang dakwah bil-hal Muhammadiyah perspektif pendidikan dan sosial. Gerakan pendidikan dan sosial Muhammadiyah salah satu bentuk amal usaha yang dikembangkan oleh organisasi Muhammadiyah termasuk Muhammadiyah Kota Sorong. 
Syarifah Kilwarany, "Peran Organisasi Muhammadiyah Dalam Pendidikan Islam Di Kota Sorong". Pokok pembahasanya tentang peran dan upaya-upaya Organisasi Muhammadiyah dalam mengembangkan kualitas pendidikan Islam di Kota Sorong. Lembaga pendidikan Muhammadiyah Kota Sorong mampu menjaring pelajar untuk masuk di Sekolah maupun di Perguruan Tinggi Muhammadiyah, serta banyak alumni dari lembaga pendidikan Muhammadiyah yang turut berperang dalam membantu mengembangkan pendidikan di Kota Sorong.

Mahfudlah Fajrie," Strategi Dakwah Muhammadiyah di Kabupaten Demak Periode 2006-2011 (Studi Analisis Strategi dan Metode Dakwah)”. Strategi dakwah Pimpinan Muhammadiyah di Kabupaten Demak periode 20062011 yaitu strategi dakwah dengan mengedepankan ajaran Islam sesuai dengan syari'at, membentuk lembaga bimbingan manasik haji, membangun budaya dialog dan pembinaan generasi muda, dan Strategi dakwah Muhammadiyah melalui budaya (kultural) membuat pandangan dan dakwah melalui pemberdayaan umat di bidang pendidikan, ekonomi, sosial dan kesehatan.

Abd. Fattah Wibisono, "Model dan Strategi Dakwah Muhammadiyah dalam Pembinaan Ummat di Tengah Dinamika Masyarakat Saat Ini”. Pokok pembahasannya adalah Muhammadiyah melakukan revitalisasi keluarga. Keluarga berdasarkan pandukan dalam Pedoman Hidup Islami Muhammadiyah, difungsikan sebagai media sosialisasi nilai-nilai ajaran Islam, kaderisasi, pelansung dan penyempurna gerakan dakwah, media pemberian keteladanan dan 
pembiasaan amal Islami dan kehidupan Islami dalam bentuk pergaulan saling mengasihi, menghormati, saling menghargai, dan menyayangi.

Muhammadiyah mengoptimalisasi mesin persyarikatan dalam bentuk pemberdayaan ranting dan amal usaha secara maksimal sebagai media dakwah. Pimpinan persyarikatan dan pimpinan amal usaha baik bidang pendidikan, kesehatan dan sosial secara aktif dan sungguh-sungguh berkerja sama mengefektifkan gerakan dakwah di ranting dan amal usaha. Kedahsyatan pengaruh media elektronik dan teknologi informasi dalam membentuk pola pikir dan prilaku masyarakat, merupakan keniscayaan dakwah Muhammadiyah memanfaatkan media elektronik dan teknologi informasi sebagai media dakwah.

Dari uraian diatas, dapat disimpulkan bahwa penelitian tersebut secara umum mengambarkan strategi dakwah Muhammadiyah diterapkan di masyarakat secara umum dan seacra khusus dilingkungan Muhammadiyah sendiri. Secara khusus telah dibahas tentang aktivitas dakwah bil-hal Muhammadiyah di bidang pendidikan dan sosial di Kota Sorong dan peran organisasi Muhammadiyah dalam pendidikan Islam di Kota Sorong. Penelitian itu, belum ada yang membahas secara pesifik dakwah Muhammadiyah di lembaga pendidikan.

Muhammadiyah Kota Sorong memulai gerakan amal usaha di bidang pendidikan. Bukti nyata amal usaha Muhammadiyah Kota Sorong yaitu telah mendirikan lembaga pendidikan yang berjumlah 9 perguruan Muhammadiyah, mulai dari Taman Kanak-Kanak hingga Peguruan Tinggi. Lembaga pendidikan Muhammadiyah selain untuk mencerdaskan anak-anak bangsa juga didesain seabagi wahana medan dakwah Islam dan untuk mencetak kader-kader 
Muhammadiyah. Hal inilah Muhammadiyah memerlukan strategi dakwah di lembaga pendidikan Muhammadiyah.

Strategi dan metode dakwah Muhammadiyah yang diterapkan di masyarakat akan berbeda strategi dakwah Muhammadiyah di lembaga pendidikan. menurut pengamatan penulis, dengan latar belakang kondisi sosial Kota Sorong terutama di lembaga pendidikan, maka perlu adanya strategi, manajemen dan pengelolaan dakwah Muhammadiyah dengan baik, agar dakwahnya berhasil dan pesan yang ingin disampaikan dapat diterima oleh siswa, mahasiswa dan masyarakat secara umum.

Secara komprehensif penulis merasa belum adanya penelitian mengenai strategi dakwah Muhammadiyah di lembaga pendidikan. Hal inilah yang membuat penulis tertarik untuk melakukan penelitian terhadap dakwah Muhammadiyah di lembaga pendidikan Muhammadiyah. Karena Muhammadiyah melakukan strategi dakwah di lembaga pendidikan Muhammadiyah dengan menerapkan pendidikan Kemuhammadiyahan dan pengkaderan melalui wadah organisasi badan otonom Muhamamdiyah.

Kesemua penelitian itu tidak ada menyinggung tentang dakwah Muhamamdiyah di Perguruan Tinggi Muhamamdiyah. Di Perguruan Tinggi Muhammadiyah (Universitas Muhammadiyah Sorong) mahasiswa banyak dari kalangan non Islam, maka Muhammadiyah melakukan strategi dakwah dengan seluruh mahasiswa tetap di wajibkan mengkuti mata kuliah pendidikan 
kemuhammadiyahan. Hal inilah perbedaan sangat menarik dari peneltian sebelumnya.

\section{H. Sistematika Pembahasan}

Penelitian ini terdiri dari lima bab, dan setiap bab terdiri dari beberapa sub bab, yaitu:

Bab pertama merupakan pendahuluan meliputi latar belakang, rumusan masalah, tujuan penelitian, manfaat penelitian, pengertian judul, kerangka teori, penelitian terdahulu dan sistematika pembahasan. Bab dua tinjauan pustaka meliputi strategi dakwah, organisasi Muhammadiyah dan lembaga pendidikan. Bab tiga membahas tentang metodologi meliputi pendekatan dan jenis penelitian, lokasi penelitian, teknik pengumpulan data dan teknik analisis data.

Bab empat adalah hasil penelitia berisi tentang profil lembaga, wujud dakwah Muhammadiyah dibidang pendidikan, strategi dakwah Muhammadiyah melalui lembaga pendidikan dan implikasi penelitian; dakwah Muhammadiyah melalui lembaga pendidikan. Bab lima merupakan bab penutup meliputi kesimpulan dan saran.

\section{DAFTAR PUSTAKA}

Abdurahman, Asyumi. Pedoman Hidup Islam Warga Muhammadiyah. Yogyakarta: Suara Muhammadiyah. 2003.

Ali, Hasniyati Gani. Ilmu Pendidikan Islam. Jakarta: Quantum Teaching. 2008.

Amin, Samsul Munir. Rekontruksi Pemikiran Dakwah Islam. Jakarta: Amzah. 2008.

Arif, Arifuddin. Pengantar Ilmu Pendidikan Islam. Jakarta: Kultura. 2008.

Arifin, Anwar. Dakwah Kontemporer (Sebuah Studi Komunikasi). Yogyakarta: Graha Ilmu. 2011 
Barulazi. skripsi Aktivitas Muhammadiya Dalam Dakwah Bil Hal Di Kota Sorong; Perspekstif Gerakan Pendidikan Dan Sosial”. Sorong : STAIN Sorong Press. 2013.

Daradjat, Zakiyah. Ilmu Pendidikan Islam, Jakarta: Bumi Aksara. 1992.

Departemen Agama RI. Al-Qura'an dan Terjemahannya. Bandung: J-ART. 2005.

Departemen Pendidikan Nasioanl, Kamus Bahasa Indonesia, Jakarta: Pusat Bahasa. 2008.

Hambali, Hamdan. Ideologi dan Strategi Muhammadiyah. Yogyakarta: Suara Muhammadiyah. 2010.

Hasbullah. Dasar-dasar Ilmu Pendidikan. Jakarta: Raja Grafindo Persada.1999.

Ibnu Salmi, dkk. Studi Muhammadiyah (Kajian Historis, Ideologi, dan Organisastoris). Surakarta: LPID. 2009.

Ihsan, Fuad Ihsan. Dasar-dasar Kependidikan. Jakarta: Rineka Cipta. 2004.

Ilahi, Wahyu. Komunikasi Dakwah. Bandung: Remaja Rosdakarya. 2008.

--------- dan Harjani, Hefni. Sejarah Dakwah. Jakarta: Kencana. 2010.

Ismail, Ilyas. Filsafat Dakwah (Rekayasa Membangun Agama dan Peradaban Islam). Jakarta: Kencana. 2011.

Mughni, Syafiq A.. Makalah Seminar Pra-Muktamar Muhammadiyah ke-46. di Universitas Muhammadiyah Sumatera Utara. 2009.

Mujib, Abdul. Ilmu Pendidikan Islam. Jakarta: Kencana. 2006.

Mulkhan, Abdul Munir. Pemikiran Kyai Haji Ahmad Dahlan, Muhammadiyah dalam Perspektif Perubahan Sosial. Jakarta: Bumi Aksara. 1990.

Mujahid, Abu. Sejarah Muhammadiyah; Gerakan Tajdid di Indonesia. Bandung: Toobagus Publishing. 2013.

Nashir, Haedar. Manhaj Gerakan Muhammadiyah Ideologi, Khittah, dan Langkah. Yogyakarta: Suara Muhammadiyah. 2013.

Pimpinan Pusat Muhammadiyah . Anggaran Dasar dan Anggaran Rumah Tangga Muhammadiyah. Yogyakarta; Pecetakan Persatuan. 2005.

Saebani, Beni Ahmad. Ilmu Pendidikan Islam, Bandung: Pustaka Setia, 2009.

Saputra, Wahidin. Pengantar Ilmu Dakwah. Jakarta: Raja Grafindo Persada. 2012.

Satir, Muhammad Pengembangan Kurikulum Materi Pendidikan Islam. Yogyakarta: Ardana Media. 2010.

Shabron, Sudarno. Studi Kemuhammadiyahan. Surakarta: LPID. 2008.

Suwarno, M. Margono Poespa. Gerakan Muhammadiyah. Yogyakaarta: persatuan Offiset. 1995.

Umar, Bukhari. Ilmu Pendidikan Islam. Jakarta: Amzah, 2010.

Zuhairini. Filsafat Pendidikan Islam. Jakarta: Departemen Agama, 2004. 